\title{
Uniform Nonlinear Constitutive Model and Parameters for Clay in Different Consolidation Conditions Based on Regression Method
}

\author{
Tao Cheng, ${ }^{1}$ Keqin Yan, ${ }^{1}$ Huazhi Zhang, ${ }^{1}$ Xianfeng Luo, ${ }^{1}$ and Shengfang $\mathrm{Li}^{2}$ \\ ${ }^{1}$ School of Civil Engineering, Hubei Polytechnic University, Huangshi 435003, China \\ ${ }^{2}$ School of Chemical and Material Engineering, Hubei Polytechnic University, Huangshi 435003, China \\ Correspondence should be addressed to Tao Cheng; chtcdy@gmail.com
}

Received 19 December 2013; Accepted 3 April 2014; Published 6 April 2014

Academic Editor: Fei Kang

Copyright (C) 2014 Tao Cheng et al. This is an open access article distributed under the Creative Commons Attribution License, which permits unrestricted use, distribution, and reproduction in any medium, provided the original work is properly cited.

The nonlinear constitutive relations of clay are investigated considering different initial conditions. Highly compressible clay is selected as the test sample. Two groups of tri-axial compression tests are performed, respectively, after $K_{0}$ consolidation and isotropic consolidation. On the basis of the framework of $E \sim v$ model, a uniform nonlinear constitutive model is proposed by fitting the test data. With the average slope of the unloading-reloading curve selected as the unloading modulus, the unloading function is constructed as the loading-unloading criterion. Moreover, a comparison between the experimental stress-strain curves and the results predicted by the constitutive model is made. It is shown that the prediction is reasonable, which can reflect the stress-strain behavior of the soil under the $K_{0}$ consolidation and isotropic consolidation conditions. The maximum relative error of the two series of curves is not remarkable, less than $6 \%$.

\section{Introduction}

In geotechnical engineering, the nonlinearity nature of soil not only is influenced by a stress path but also has a close relationship with a load and a loading method. Therefore, it is a key to choose a suitable mechanical model of the medium material in geotechnical calculation.

Duncan $[1,2]$ presented an incremental nonlinear elastic model based on this relationship curve, which was generally called the Duncan-Chang model. A hyperbolic function was adopted to fit the tri-axial experiment stress-strain curve of soil [3]. The hyperbolic model has been a widely used nonlinear constitutive relationship for clay because of its simple model structure and accessible parameters [4]. This constitutive model was based on the data of tri-axial shear tests [5] under regular loading path. Thus, it had a simple framework and can raise the calculation efficiency.

Subsequently, some researchers attempted to improve the Duncan-Chang model and studied different soil constitutive models and their influence on results [6-8]. They concluded that the modified Duncan-Chang model was a good compromise between prediction accuracy and availability of parameters from conventional tri-axial compression testing. It was developed for cohesionless soils that had two parts $[9,10]$ : an elastic nonlinear part and two mechanisms of plasticity. It was allowed to take into account the nonlinearity of the behavior at low stress level for overconsolidated materials [11]. The description of the model and its parameters are given [12]. To consider the effect of different stress paths, some scholars $[13,14]$ developed the Duncan-Chang model, derived a formula of tangent elastic modulus under different stress paths, and provided approximate elastic-plastic models for clay $[15,16]$. Lode parameter was introduced into DuncanChang model to reflect the effect of intermediate principal stress [17]. To consider the soil structural damage during loading, the concept of damage rate was introduced to modify Duncan-Chang model $[18,19]$.

In these modified models, the initial stress state was assumed to be isotropic. However, the initial stress state of naturally deposited clay is usually anisotropic, known 

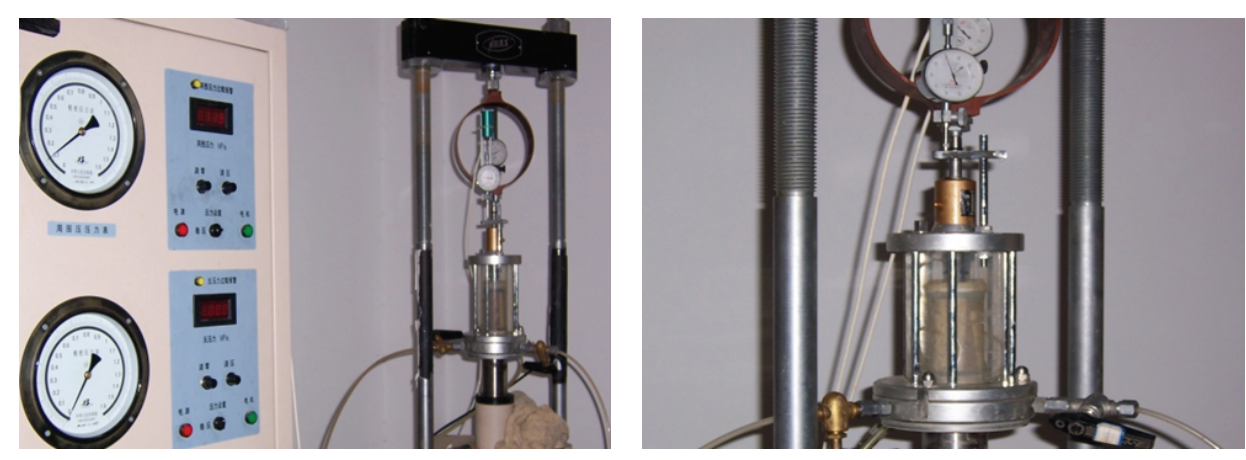

FIgURE 1: Experiment testing machine and sample.

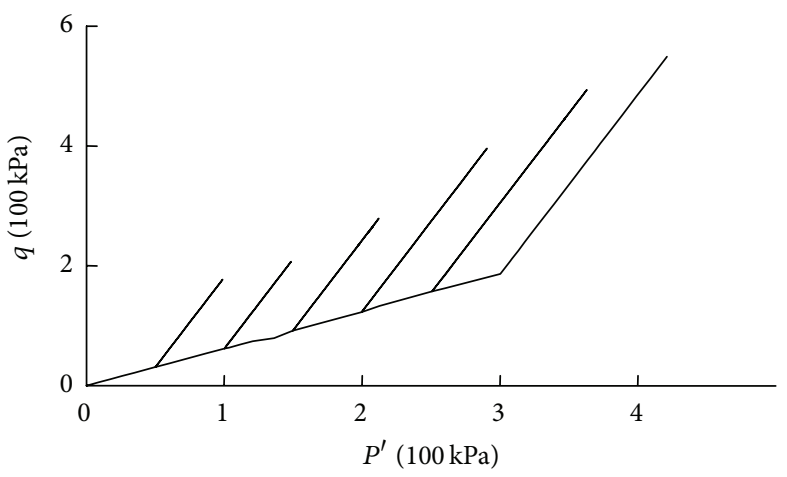

(a) $C K_{0} D$ tri-axial compression test

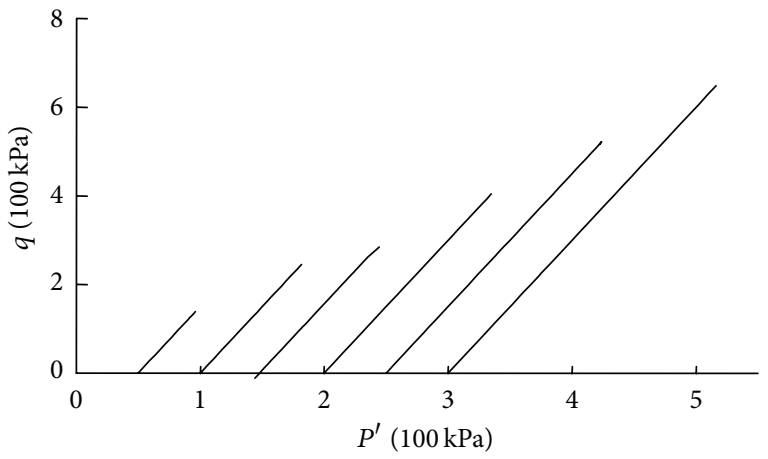

(b) $C D$ tri-axial compression test

FIGURE 2: Stress path of compression experiment.

as $K_{0}$ consolidation [20]. The anisotropic initial stress and strain states result in different strength and deformation characteristics, and the constitutive relationship was different from that of isotropic stress states [21]. To overcome these differences, a unified nonlinear constitutive model was proposed for clay under different initial conditions. Two groups of tri-axial compression tests for highly compressible clay are performed, as $K_{0}$ consolidation and isotropic consolidation. By fitting the test data, a factor of anisotropic consolidation is introduced into the framework of $E \sim v$ model to construct a uniform nonlinear constitutive model. With the average slope of the unloading-reloading curve selected as the unloading modulus, the unloading function is constructed as the loading-unloading criterion. Furthermore, the rationality of this model is checked. A comparison is made between the experimental stress-strain curves and the computational results predicted by the constitutive model. It is shown that the model can reflect the stress-strain behavior of the soil under the $K_{0}$ consolidation and isotropic consolidation conditions.

\section{Experiment Analysis}

2.1. Sample Preparation. In this study, natural saturation clay sampled from Wuhan is studied. Considering the anisotropic initial stress and strain state, two parallel drain tri-axial tests were carried out. In these tests, the static lateral pressure coefficient $K_{0}=\sigma_{3} / \sigma_{1}$ was set to 0.562 [22]. Then, two parallel lateral confinement compression tests were carried out to acquire the natural compression coefficient $a$, and it equals $0.567 \mathrm{MPa}^{-1}$. Some other physical properties of the studied clay are shown in Table 1.

Considering the inevitable influence of disturbance and the difference characteristics in mechanics and physics of undisturbed soil sampling from different place, definite divergence was inevitable. Therefore, the moisture content is decided by field investigation. The remodeling soil sample of test passed by a series process: the undisturbed soil samples are made into uniform saturation samples, then tamping in 5 layers in tramper, and then extraction air before test. After the sample is installed, counter-pressure saturation is carried out until the saturation reaches larger than 99\%. Then tri-axial shear test can be carried out under specified stress path.

2.2. Tri-Axial Test Paths. Consolidated trained tri-axial compression tests $(C D)$ were carried out in two different stress paths, by using SJ-1AG conventional tri-axial testing machine (shown as Figure 1). One test path is drained tri-axial compression tests under $K_{0}$ consolidation conditions $\left(C K_{0} D\right)$. As comparison, the other is chosen as isotropic consolidation $(C D)$. The stress paths of the two group tests are shown in Figure 2.

In the $C D$ test, prophase average consolidation pressures $p_{a}$ were varied from 50 to $300 \mathrm{kPa}$, and the interval between 
TABLE 1: Physical properties of the studied clay.

\begin{tabular}{lccccccc}
\hline Physical property & $w(\%)$ & $\rho /\left(\mathrm{g} / \mathrm{cm}^{3}\right)$ & $G_{S}$ & $w_{P}(\%)$ & $w_{L}(\%)$ & $e$ & $S_{r}(\%)$ \\
\hline Value & 28.53 & 1.961 & 2.697 & 28.18 & 47.82 & 0.897 & 98.9 \\
\hline
\end{tabular}

TABLE 2: Initial stresses of $C K_{0} D$ tests.

\begin{tabular}{lcc}
\hline$p_{a} / \mathrm{kPa}$ & $\sigma_{1} / \mathrm{kPa}$ & $\sigma_{3} / \mathrm{kPa}$ \\
\hline 50 & 70.6 & 39.7 \\
100 & 141.3 & 79.4 \\
150 & 211.9 & 119.1 \\
200 & 282.4 & 158.7 \\
250 & 353.1 & 198.4 \\
300 & 423.9 & 238.2 \\
\hline
\end{tabular}

every single test was $50 \mathrm{kPa}$. The tri-axial compression test cannot be carried out unless the pore pressure dissipation reaches 95\%; otherwise consolidation will be sustained. Similarly, $C K_{0} D$ tests also consist of 6 series of parallel tests with different consolidation pressures. In consolidation, the axial pressure and lateral pressure are added step by step until initial consolidation pressure $p_{a}$ reaches $50 \sim 300 \mathrm{kPa}$. Unlike the $C D$ test, the initial $\sigma_{3}$ is different from $\sigma_{1}$ in the $C K_{0} D$ tests. As $p_{a}=\left(\sigma_{1}+2 \sigma_{3}\right) / 3$, the initial stresses of $C K_{0} D$ tests are determined and shown in Table 2.

2.3. Result of Test. Figure 3 is the relationship between generalized shear stress $q$ and generalized shear strain $\bar{\varepsilon}$ as initial consolidation pressure is $200 \mathrm{kPa}$ of two different stress paths. Similarly, Figure 4 shows the relationship between generalized shear stress $q$ and generalized volumetric strain $\varepsilon_{v}$.

The two figures indicate that there are different stressstrain relationships for different stress paths. In the initial stage of load, the stress in isotropic pressure test (CD test) increases slower than that of $K_{0}$ consolidation $\left(C K_{0} D\right.$ test). In the later stage, both $\bar{\varepsilon}$ and $\varepsilon_{v}$ in $C D$ test increase faster. Finally, the peak values in the $C K_{0} D$ test are slightly above those of $C D$ test. It is because the lateral deformation constraints in $C K_{0} D$ test are less than $C D$. Thus, it is also shown that the influence of initial anisotropy on the constitutive relationship cannot be neglected.

\section{Framework of Model}

3.1. Tangent Elastic Modulus $E_{t}$. Assuming that the elastic relationship of $\left(\sigma_{1}-\sigma_{3}\right) \sim \varepsilon_{1}$ is hyperbolic based on the generalized Hooke law and test data, we choose the tangent elastic model (E v model) as the model framework. In view of initial anisotropy, we introduce the lateral pressure coefficient into this model. Thus, it can be expressed as

$$
E_{t}=E_{i}\left[1-\frac{R_{f}(1-\sin \varphi)\left(\sigma_{1}-\sigma_{3}\right)^{0.85 / K_{0}}}{2 c \cos \varphi+2 \sigma_{3} \sin \varphi}\right]^{2}
$$

where $K_{0}$ is the lateral pressure coefficient; $E_{t}$ is the tangent elastic modulus; $R_{f}$ is the damage ratio, $R_{f}=\left(\sigma_{1}-\sigma_{3}\right)_{f} /\left(\sigma_{1}-\right.$ $\left.\sigma_{3}\right)_{\mathrm{ult}} ;\left(\sigma_{1}-\sigma_{3}\right)_{\mathrm{ult}}$ is the asymptotic value of curve $\left(\sigma_{1}-\sigma_{3}\right) \sim \varepsilon_{1}$; $\left(\sigma_{1}-\sigma_{3}\right)_{f}$ is the breakdown strength and it can be determined by the Mohr Coulomb failure criterion:

$$
\left(\sigma_{1}-\sigma_{3}\right)_{f}=\frac{\left(2 c \cos \varphi+2 \sigma_{3} \sin \varphi\right)}{(1-\sin \varphi)} .
$$

In the equation above, $c$ denotes the cohesive strength of soil; $\varphi$ denotes the internal friction angle of soil; $\sigma_{1}$ and $\sigma_{3}$ denote the axial and radial stresses, respectively, based on the nonlinear regression analysis method [23]; the initial modulus of the curve $E_{i}$ can be determined by the following:

$$
E_{i}=K p_{a}\left(\frac{\sigma_{3}}{p_{a}}\right)^{n},
$$

where $p_{a}$ is the atmospheric pressure; $K$ and $n$ are experiment parameters. In log-log coordinates, there is linear relationship between $E_{i}$ and $\sigma_{3}$ and the slope is $n . K$ is the intercept of the line when $\sigma_{3}=p_{a}$.

3.2. Tangent Poisson Ratio $v_{t}$. The relationship between $\varepsilon_{1}$ and $\varepsilon_{3}$ is always hyperbolic. Equation (4) shows the expression of the Poisson ratio $v_{t}$ deduced as

$$
v_{t}=\frac{v_{i}}{\left(1-D \varepsilon_{1}\right)^{2}}
$$

where $D$ is a test parameter determined by the slope of the linear relationship between $\varepsilon_{r} / \varepsilon_{1}$ and $\varepsilon_{r}, \varepsilon_{r}=\left(3 \varepsilon_{v}-\varepsilon_{1}\right) / 2$; $\varepsilon_{v}, \varepsilon_{1}$ represent the volumetric strain and the axial strain, respectively; $v_{i}$ is the Poisson ratio and can be determined by the following:

$$
v_{i}=G-F \log \left(\frac{\sigma_{3}}{p_{a}}\right) .
$$

In the equation above, $G$ and $F$ are experiment parameters and can be determined according to the curve between $v_{i}$ and $\sigma_{3}$ in semilog coordinates. $F$ is the slope of the $\nu_{i}-\log \sigma_{3}$ line and $G$ is the intercept of the line when $\sigma_{3}=p_{a}$. Axial strain $\varepsilon_{1}$ can be determined by the following:

$$
\begin{aligned}
\varepsilon_{1}= & \left(\sigma_{1}-\sigma_{3}\right) \\
& \times\left(E_{i}\left[1-\frac{R_{f}(1-\sin \varphi)\left(\sigma_{1}-\sigma_{3}\right)^{0.85 / K_{0}}}{2 c \cos \varphi+2 \sigma_{3} \sin \varphi}\right]\right)^{-1} .
\end{aligned}
$$

3.3. Unloading Modulus $E_{u r}$. Based on experimental data, Duncan assumed that the unloading modulus $E_{\text {ur }}$ does not change with the change of $\sigma_{1}-\sigma_{3}$. It is only related to $\sigma_{3}$. 


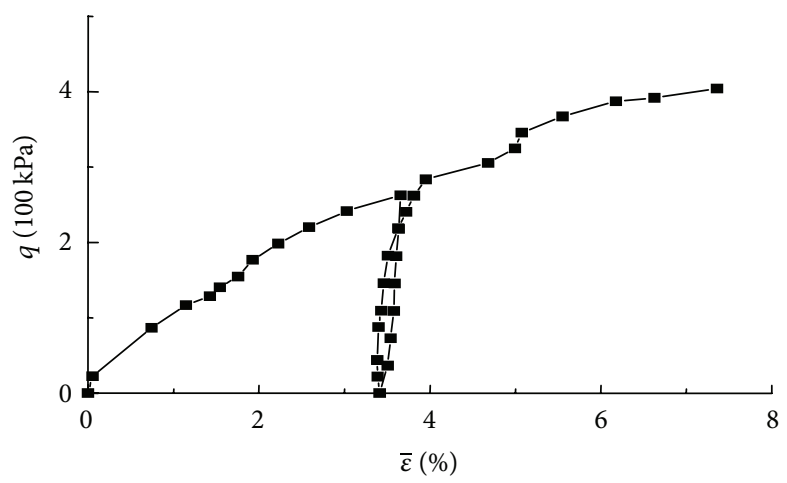

(a) $C D$ path

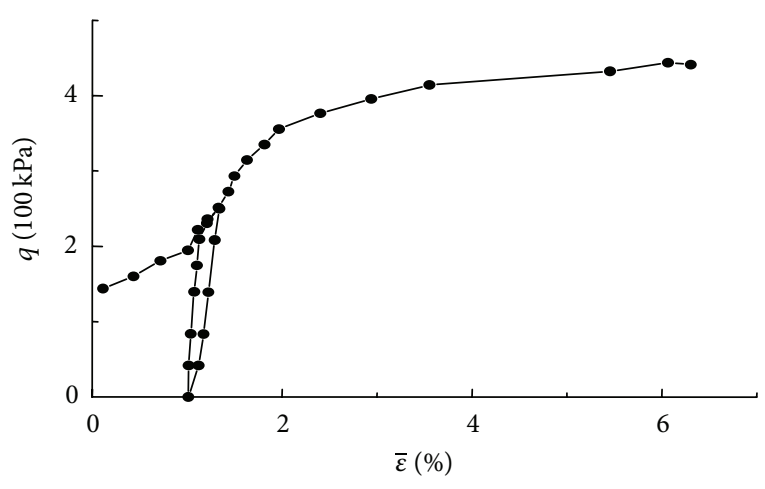

(b) $C K_{0} D$ path

FiguRE 3: $q \sim \bar{\varepsilon}$ curves of different compression experiments.

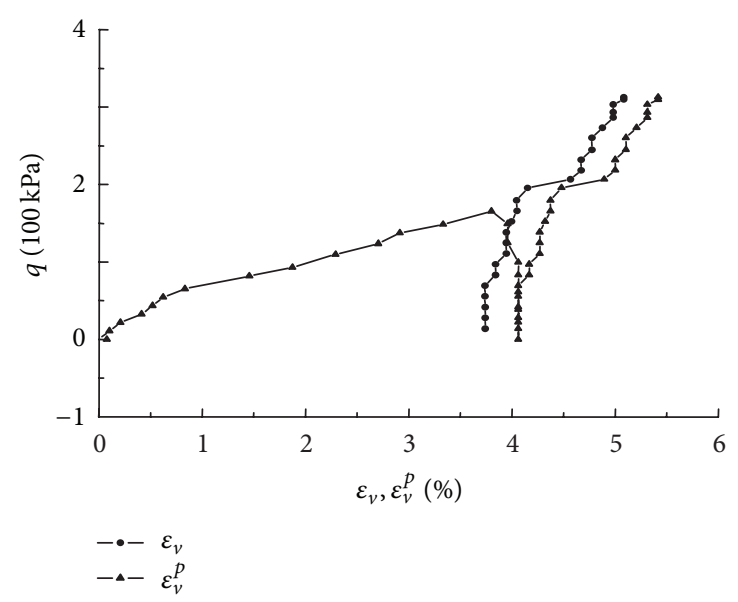

(a) $C D$ path

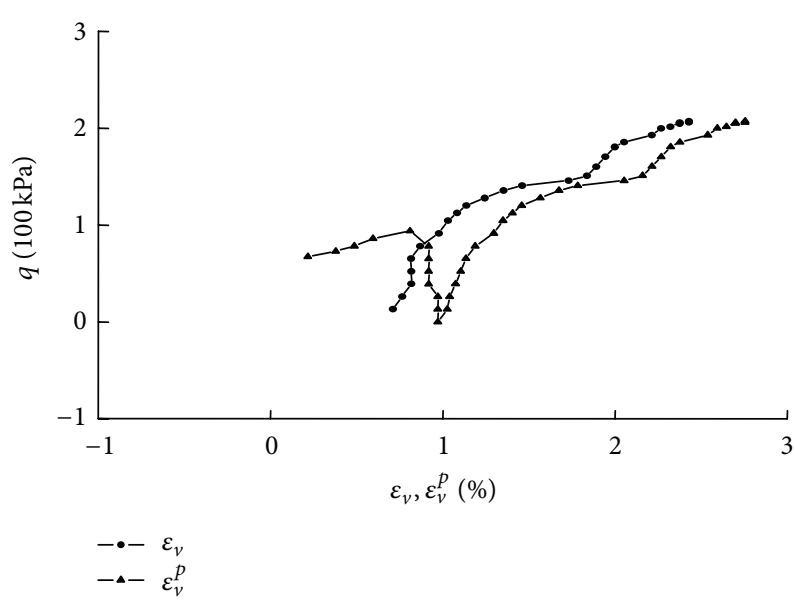

(b) $C K_{0} D$ path

FIGURE 4: $q \sim \varepsilon_{v}$ curves of different compression experiments.

According to experimental unloading-reloading curves, based on the nonlinear regression analysis method [23], the relationship between $E_{\mathrm{ur}}$ and $\sigma_{3}$ can be drawn. It is approximately linear in the logarithmic coordinates, as shown in in the following:

$$
E_{\mathrm{ur}}=K_{\mathrm{ur}} p_{a}\left(\frac{\sigma_{3}}{p_{a}}\right)^{n},
$$

where $K_{\mathrm{ur}}$ is an empirical constant and can be expressed as the intercept of the line between $\log \left(E_{\mathrm{ur}} / p_{a}\right)$ and $\log \left(\sigma_{3} / p_{a}\right)$ when $\sigma_{3}=p_{a}$.

\section{Constitutive Model}

4.1. Parameters for the Model. In $K_{0}$ consolidation, the clay appears to be anisotropic state. For $p$ equals 100, 200, and $300 \mathrm{kPa}$, the lateral pressure $\sigma_{3}$ can be determined from $K_{0}$. The corresponding values are $79.4,158.7$, and $238.1 \mathrm{kPa}$. By the relationship between $\varepsilon_{1} /\left(\sigma_{1}-\sigma_{3}\right)$ and $\varepsilon_{1}$ (shown in Figure 5), the intercept $1 / E_{i}$ can be determined. The Initial elastic modulus $E_{i}$ can be calculated correspondingly. It is shown in Table 3.
TABLE 3: Initial tangent elastic modulus $E_{i}$.

\begin{tabular}{lccc}
\hline$\sigma_{3} / 100 \mathrm{kPa}$ & $1 / E_{i}$ & $E_{i} / 100 \mathrm{kPa}$ & $\overline{E_{i}} / 100 \mathrm{kPa}$ \\
\hline 0.794 & 0.0045 & 222.2 & \\
1.587 & 0.0040 & 250.0 & 242.8 \\
2.381 & 0.0039 & 256.0 & \\
\hline
\end{tabular}

In $\log$ - $\log$ coordinates, the relationship between $E_{i}$ and $\sigma_{3}$ is almost linear, and it is shown in Figure 6.

Figure 6 indicates when $\sigma_{3}=100 \mathrm{kPa}$, the corresponding vertical coordinate $K=230.1$, and the slope $n$ of the line equals 0.139 .

Based on the result of test, axial strain $\varepsilon_{1}$ and volumetric strain $\varepsilon_{v}$ are determined; after conversion between strains, the relationship curve can be drawn between $\varepsilon_{r} / \varepsilon_{1}$ and $\varepsilon_{r}$. In view of that we can determine the parameter $G$ in fitting line (Figure 8) only when $\sigma_{3}=100 \mathrm{kPa}$, and we choose some test data which can cover $100 \mathrm{kPa}$. That is, $\sigma_{3}=39.7 \mathrm{kPa}, 79.4 \mathrm{kPa}$, and $158.7 \mathrm{kPa}$ (as Table 1). Thus, the curve of $\varepsilon_{r} / \varepsilon_{1} \sim \varepsilon_{r}$ is shown in Figure 7. 


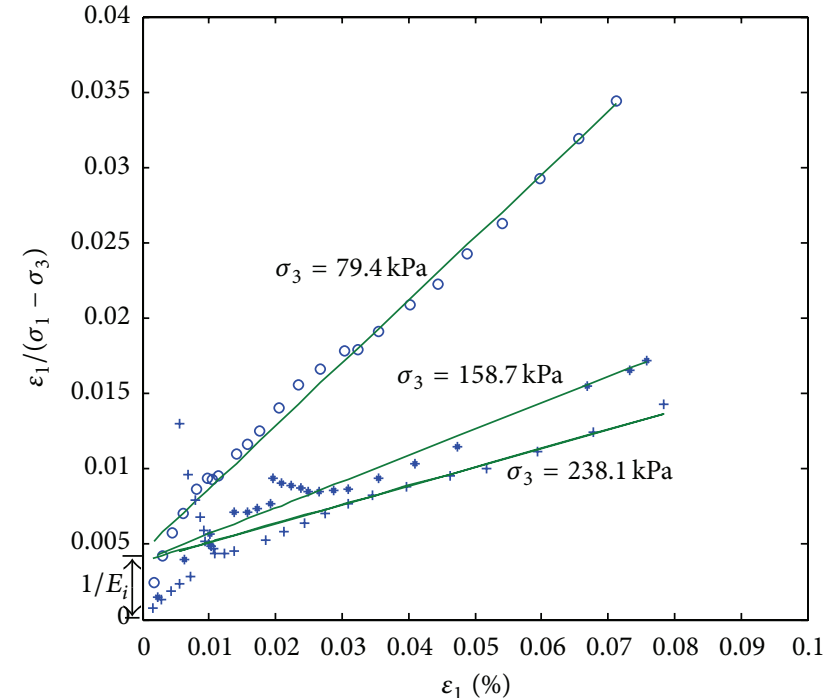

Figure 5: $\varepsilon_{1} /\left(\sigma_{1}-\sigma_{3}\right) \sim \varepsilon_{1}$ curves of different compression experiments.

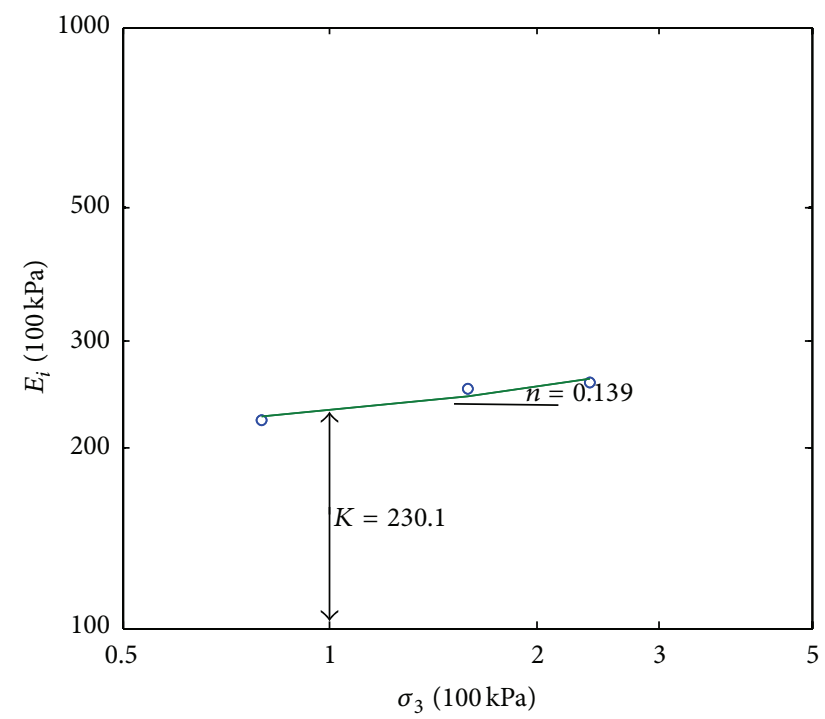

Figure 6: $E_{i} \sim \sigma_{3}$ curve.

Based on (5), the linear relationship between $v_{i}$ and $\sigma_{3}$ in semilog coordinates is shown in Figure 8. The figure indicates that corresponding straight slope and unit intercept are $F=$ 0.09 and $G=0.0642$.

Mohr's circle can be drawn based on parameters of limit states for different ambient pressures. It is shown in Figure 9 that $c$ equals $21 \mathrm{kPa}$ and $\varphi$ equals $31.3^{\circ}$.

$\left(\sigma_{1}-\sigma_{3}\right)_{\text {ult }}$ and $R_{f}$ are determined by the curve relationship between $\sigma_{1}-\sigma_{3}$ and $\varepsilon_{1}$. The calculation result is shown in Table 4.

Similar to the solution to elastic modulus $E_{t}$, the relationship between $E_{\mathrm{ur}}$ and $\sigma_{3}$ can be drawn in $\log$-log coordinates. It is shown in Figure 10. When $\sigma_{3}$ equals $100 \mathrm{kPa}$, the corresponding vertical coordinate $K_{\mathrm{ur}}$ equals 295.8, and the slope $n$ equals 0.362 .

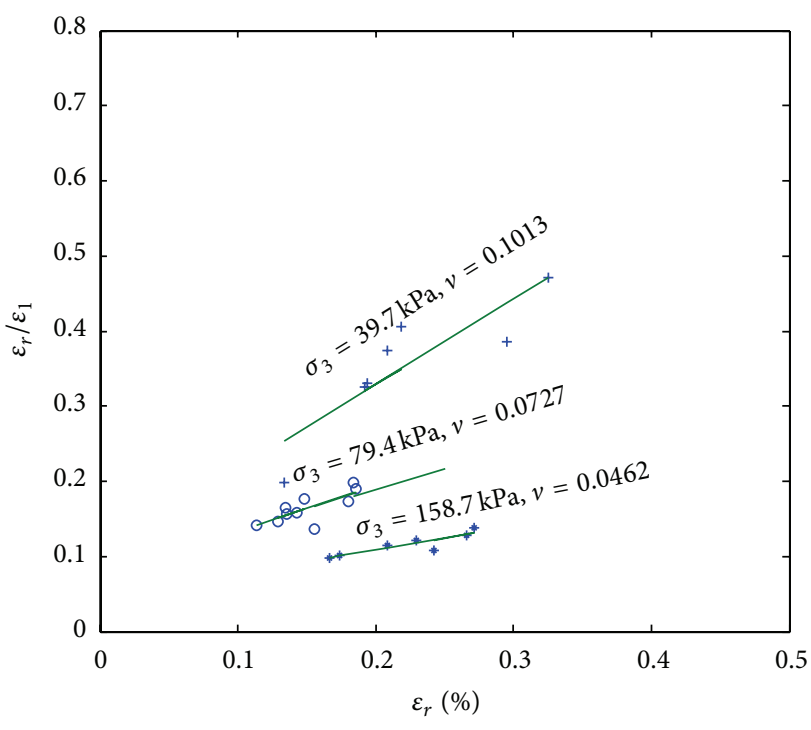

FIGURE 7: $\varepsilon_{r} / \varepsilon_{1} \sim \varepsilon_{r}$ curves.

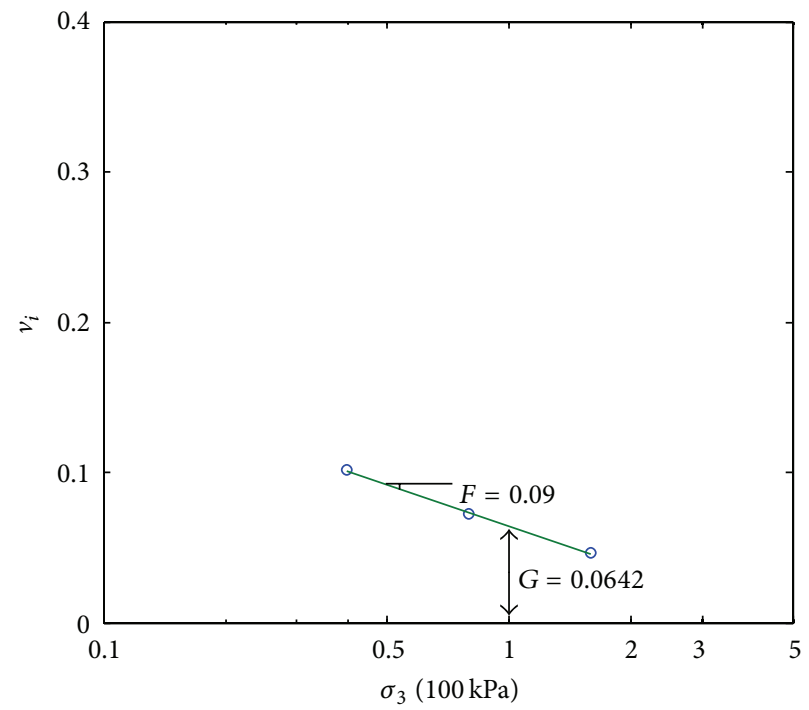

FIGURE 8: $v_{i} \sim \sigma_{3}$ curve.

TABLE 4: Limit state parameter.

\begin{tabular}{lcccc}
\hline$\sigma_{3} / 100 \mathrm{kPa}$ & $\left(\sigma_{1}-\sigma_{3}\right)_{f}$ & $\left(\sigma_{1}-\sigma_{3}\right)_{\mathrm{ult}}$ & $R_{f}$ & $\bar{R}_{f}$ \\
\hline 0.794 & 264.1 & 286.0 & 0.9140 & \\
1.587 & 446.0 & 600.0 & 0.7433 & 0.820 \\
2.381 & 630.7 & 786.0 & 0.8024 & \\
\hline
\end{tabular}

4.2. Constitutive Model. Integrating the results of the above calculation, the $E \sim v$ model can be obtained for $K_{0}$ consolidation. The tangent elastic modulus is shown in the following:

$$
E_{t}=230.1\left[1-\frac{0.394\left(\sigma_{1}-\sigma_{3}\right)^{0.85 / K_{0}}}{0.403+1.039 \sigma_{3}}\right]^{2} p_{a}\left(\frac{\sigma_{3}}{p_{a}}\right)^{0.139} .
$$




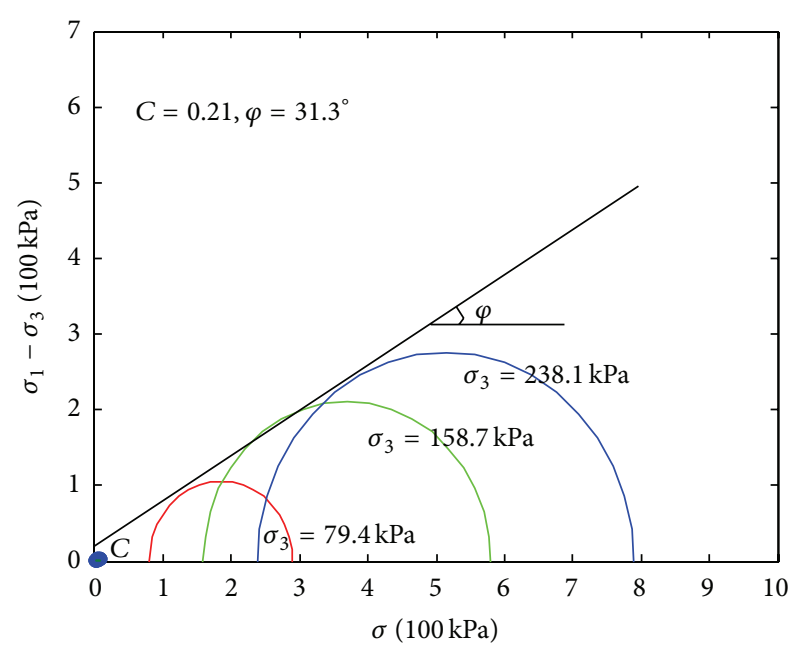

FIGURE 9: Mohr circle of shearing limit state.

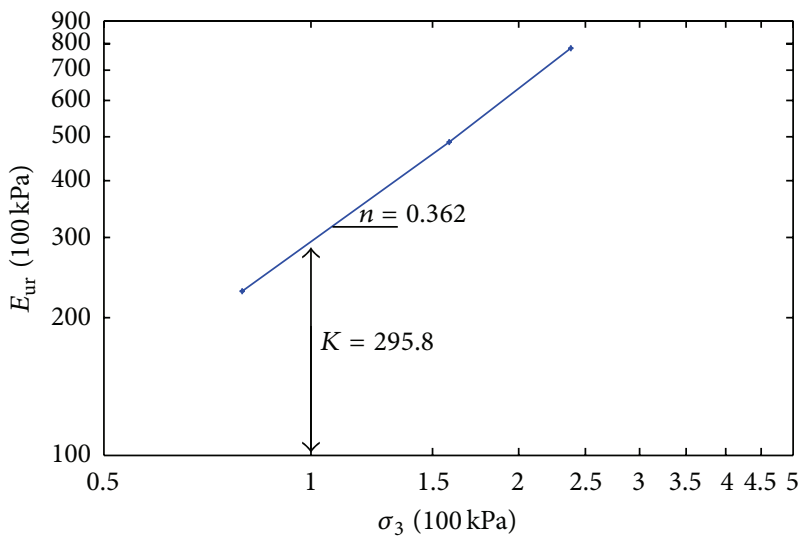

Figure 10: $E_{\text {ur }} \sim \sigma_{3}$ curve.

The tangent Poisson ratio is shown in the following:

$$
\begin{aligned}
& v_{t}=\{0.064-\left.0.09 \log \left(\frac{\sigma_{3}}{p_{a}}\right)\right\} \\
& \times\left\{1-\left(3.13\left(\sigma_{1}-\sigma_{3}\right)\right)\right. \\
& \times\left(230.1\left[1-\frac{0.394\left(\sigma_{1}-\sigma_{3}\right)^{0.85 / K_{0}}}{0.403+1.039 \sigma_{3}}\right]^{2}\right. \\
&\left.\left.\left.\quad \times p_{a}\left(\frac{\sigma_{3}}{p_{a}}\right)^{0.139}\right)^{-1}\right)\right\}^{-2} .
\end{aligned}
$$

The coefficient $K_{0}$ is determined by stress values in (8) and (9). Correspondingly, the uniform relationship between the stress and strain increments is shown in the following:

$$
\{d \sigma\}=[D]\{d \varepsilon\},
$$

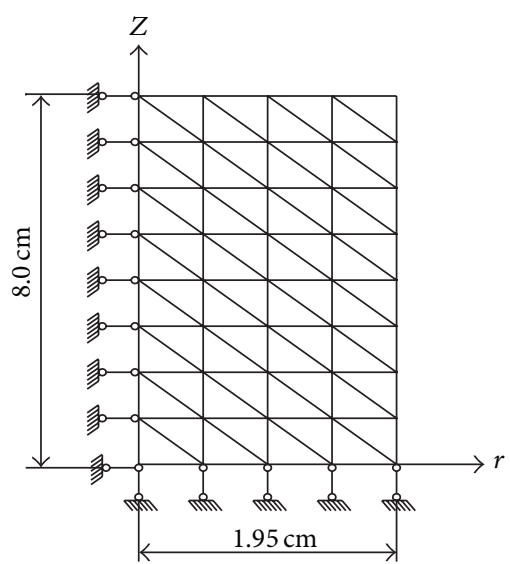

Figure 11: Computation diagram of FEA.

where $\{d \sigma\}=\left\{d \sigma_{x(r)}, d \sigma_{y(\theta)}, d \sigma_{Z}, d \tau_{x y(r z)}\right\}^{T} ;\{d \varepsilon\}=$ $\left\{d \varepsilon_{x(r)}, d \varepsilon_{y(\theta)}, d \varepsilon_{z}, d \varepsilon_{x y(r z)}\right\}^{T}$.

In $(10),[D]$ can be described as follows:

$$
[D]=\frac{E}{\left(1+v_{t}\right)\left(1-2 v_{t}\right)}\left[\begin{array}{cccc}
1-v_{t} & v_{t} & v_{t} & 0 \\
v_{t} & 1-v_{t} & v_{t} & 0 \\
v_{t} & v_{t} & 1-v_{t} & 0 \\
0 & 0 & 0 & 1-2 v_{t}
\end{array}\right]
$$

where $E$ represents the elastic modulus of clay. In the equation above, loading and unloading states can be determined by (7) and (8). At loading stage, $E=E_{t}$; at unloading stage $E_{\text {ur }}=$ $295.8 p_{a}\left(\sigma_{3} / p_{a}\right)^{0.362}$; at reloading stage, $E=E_{\text {ur }}$. This modulus is used to separate elastic strain from plastic one.

\section{Numerical Analysis}

To verify the validity of the model proposed in this paper, the authors have implemented the constitutive relationship into a finite element program and made a numerical simulation of tri-axial tests. The height and diameter of the clay sample are $8 \mathrm{~cm}$ and $3.91 \mathrm{~cm}$, respectively. Taking the symmetry of the sample into consideration, a half of the sample is adopted in the numerical simulation. In view of symmetry, horizontal displacement of nodes on the axes of symmetry is zero. Similarly, because of rigid fastening of test base, vertical constraints are applied to all the nodes of the sample. Moreover, the other two boundaries are force boundaries. The upper boundary is applied with $\sigma_{1}$ and the right is $\sigma_{3}$. The computation model is shown in Figure 11. There are 45 nodes and 643 -node triangular elements in the simulation.

The relationship of $q \sim \varepsilon_{1}$ is obtained, in which, $q$ is the shear stress of the sample and $\varepsilon_{1}$ is the average axial strain of the sample. Comparison between the numerical results and that of the corresponding test has been made. The part of comparison is shown in Figure 12.

Figure 12 indicates that the nonlinear model proposed in this paper can reflect the relationship of tri-axial shear test for $K_{0}$ consolidation (in $C K_{0} D$ test, $K_{0}=0.562$; in $C D$ test, $\left.K_{0}=1\right)$. Separation appears only at the later stage when the 


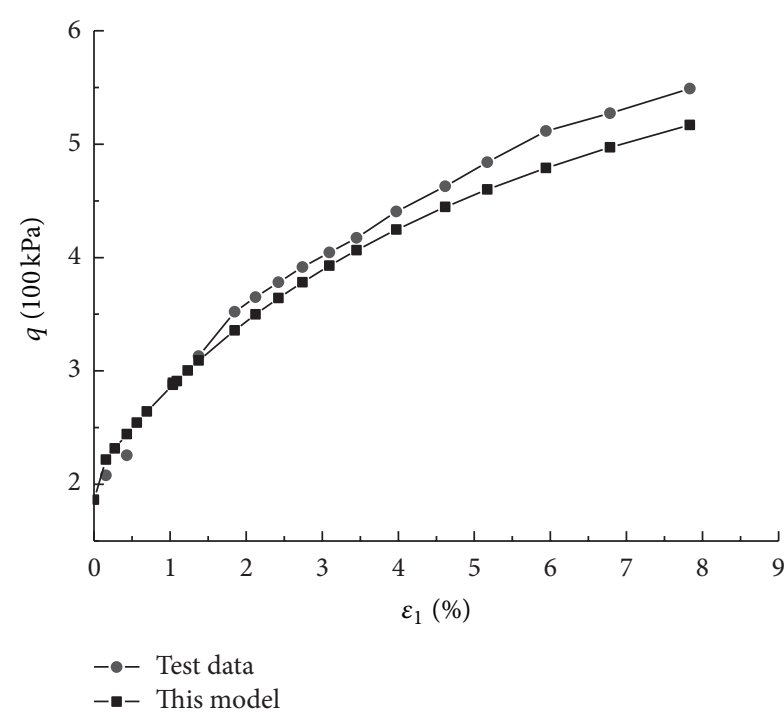

(a) $C K_{0} D$ test

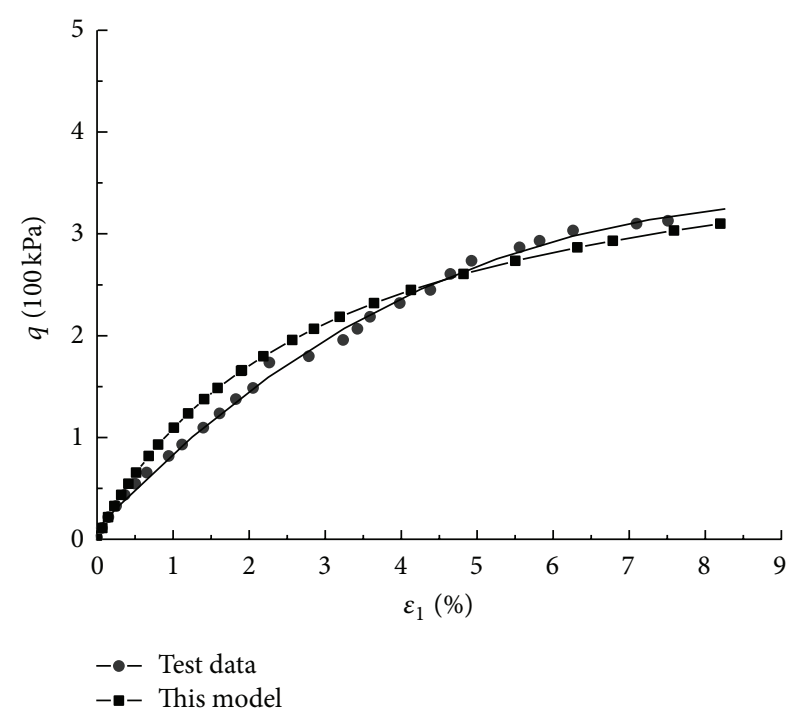

(b) $C D$ test

FIgURE 12: Comparison between numerical simulation and test curves.

sample is close to failure. At this stage, the result from test is slightly larger than that of simulation, but the maximum error is only $6.0 \%$.

\section{Conclusion}

The initial condition of natural clay is usually under $K_{0}$ stress states. To display the different mechanical characteristics, two series of initial consolidation condition tri-axial compress experiments are done. It is shown that there are some differences of a soil under isotropic conditions. In the initial stage of load, the stress in isotropic pressure test increases slower than that of $K_{0}$ consolidation. In the later stage, the shear strain in $K_{0}$ consolidation increases faster. It indicates that the influence of stress paths to the constitutive relationship cannot be neglected.

According to the tests, a factor of lateral pressure coefficient is introduced into the $E \sim v$ model. A uniform nonlinear constitutive model is proposed by fitting of the stressstrain behavior of clay with different initial conditions. Based on nonlinear regression analysis, some model parameters are provided.

With the average slope of the unloading-reloading curve selected as the unloading modulus, the constitutive relations can be promoted to an elastoplastic model. The proposed model can reflect the stress-strain relationship under $K_{0}$ conditions. Some discrepancy between the model prediction and the test data occurs at the stage close to failure. The maximum error is just $6.0 \%$.

\section{Conflict of Interests}

The authors declare that there is no conflict of interests regarding the publication of this paper.

\section{Acknowledgments}

The study was supported by the Natural Science Fund of Hubei Province under Grant 2012FKC14201, Scientific Research Fund of Hubei Provincial Education Department D20134401, and the Innovation Foundation in Youth Team of Hubei Polytechnic University under Grant Y0008. Their financial support is gratefully acknowledged.

\section{References}

[1] J. M. Duncan and C. Y. Chang, "Non-linear analysis of stress and strain in soils," Journal of Geotechnical Engineering, vol. 96, no. 5, pp. 1629-1653, 1970.

[2] J. M. Duncan and V. R. Schaefer, "Finite element consolidation analysis of embankments," Computers and Geotechnics, vol. 6, no. 2, pp. 77-93, 1988.

[3] R. L. Kondner, "Hyperbolic stress-strain response: cohesive soils," Journal of the Soil Mechanics and Foundations Division, vol. 89, no. 1, pp. 115-143, 1963.

[4] M. Khabbazian, V. N. Kaliakin, and C. L. Meehan, "Performance of quasilinear elastic constitutive models in simulation of geosynthetic encased columns," Computers and Geotechnics, vol. 38, no. 8, pp. 998-1007, 2011.

[5] K. Miyazaki, N. Tenma, K. Aoki et al., "A nonlinear elastic model for tri-axial compressive properties of artificial methanehydrate-bearing sediment samples," Energies, no. 5, pp. 40574075, 2012.

[6] B. Huang, R. J. Bathurst, and K. Hatami, "Numerical study of reinforced soil segmental walls using three different constitutive soil models," Journal of Geotechnical and Geoenvironmental Engineering, vol. 135, no. 10, pp. 1486-1498, 2009.

[7] H. I. Ling and H. Liu, "Deformation analysis of reinforced soil retaining walls-simplistic versus sophisticated finite element analyses," Acta Geotechnica, vol. 4, no. 3, pp. 203-213, 2009.

[8] A. Abdelouhab, D. Dias, and N. Freitag, "Numerical analysis of the behaviour of mechanically stabilized earth walls reinforced 
with different types of strips," Geotextiles and Geomembranes, vol. 29, no. 2, pp. 116-129, 2011.

[9] B. Cambou and K. Jafari, A Constitutive Model for Granular Materials Based on Two Plasticity Mechanisms, Constitutive Equations for Granular Non-Cohesive Soils, A.A. Balkema, Rotterdam, The Netherlands, 1987.

[10] J. H. Atkinson and G. Sallfors, "Experimental determination of stress-strain-time characteristics in laboratory and in situ tests," in Proceedings of the 10th European Conference on Soil Mechanics and Foundation Engineering, pp. 915-956, May 1991.

[11] M. Maleki, P. Dubujet, and B. Cambou, "Modélisation hiérarchisée du comportement des sols," Revue Française de Génie Civil, vol. 4, no. 7-8, pp. 895-928, 2000.

[12] O. Jenck, D. Dias, and R. Kastner, "Three-dimensional numerical modeling of a piled embankment," International Journal of Geomechanics, vol. 9, no. 3, pp. 102-112, 2009.

[13] A. Turan, M. H. El Naggar, and D. Dundas, "Investigation of induced trench method using a full scale test embankment," Geotechnical and Geological Engineering, vol. 3, no. 2, pp. 557568, 2013.

[14] J. Jalini, M. K. Jafari, A. Shafiee et al., "An investigation on effect of inclusions on heterogeneity of stress, excess pore pressure and strain distribution in composite soils," International Journal of Civil Engineering, vol. 10, no. 2, pp. 124-138, 2012.

[15] S. Likitlersuang, C. Surarak, B. Balasubramaniam et al., "Duncan-chang-parameters for hyperbolic stress strain behaviour of soft Bangkok clay," in Proceedings of the 18th International Conference on Soil Mechanics and Geotechnical Engineering (ICSMGE '13), 2013.

[16] B. Huang, R. J. Bathurst, K. Hatami, and T. M. Allen, "Influence of toe restraint on reinforced soil segmental walls," Canadian Geotechnical Journal, vol. 47, no. 8, pp. 885-904, 2010.

[17] D. W. Hight, R. Boese, A. P. Butcher, C. R. I. Clayton, and P. R. Smith, "Disturbance of the Bothkennar clay prior to laboratory testing," Geotechnique, vol. 42, no. 2, pp. 199-217, 1992.

[18] L. Z. Wang, Z. Y. Zhao, and L. L. Li, "Non-linear elastic model considering soil structural damage," Journal of Hydraulic Engineering, vol. 20, no. 1, pp. 83-89, 2004.

[19] T. Cheng and K.-Q. Yan, "Modified hyperbolic model of high compressibility clay considering strain strengthening effects," Journal of Civil, Architectural and Environmental Engineering, vol. 31, no. 5, pp. 49-53, 2009.

[20] J. A. R. Ortigao, Soil Mechanics in the Light of Critical State Theories, A.A. Balkema, Rotterdam, The Netherlands, 1995.

[21] T. Cheng, J.-T. Wang, and K.-Q. Yan, "Digitalization modeling system for constitutive relation of geomaterial," Journal of China University of Mining and Technology, vol. 16, no. 3, pp. 338-343, 2006.

[22] T. Cheng, J. T. Wang, K. Q. Yan, and G. Li, "Coupling analysis method for elastoplastic consolidation of clay considering stress paths," Chinese Journal of Rock Mechanics and Engineering, vol. 27, no. 2, pp. 403-409, 2008.

[23] C. T. Zheng, Y. Y. Cai, Z. B. Qi et al., "Use regression analysis to study the improved Duncan-Chang model," Journal of Wuhan University of Technology, vol. 34, no. 4, pp. 108-112, 2012. 


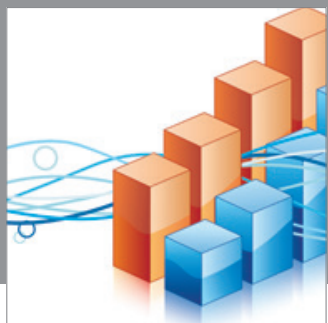

Advances in

Operations Research

mansans

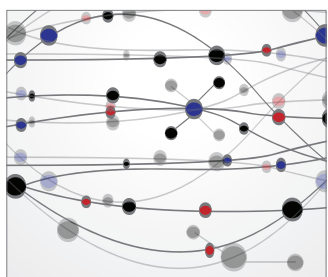

The Scientific World Journal
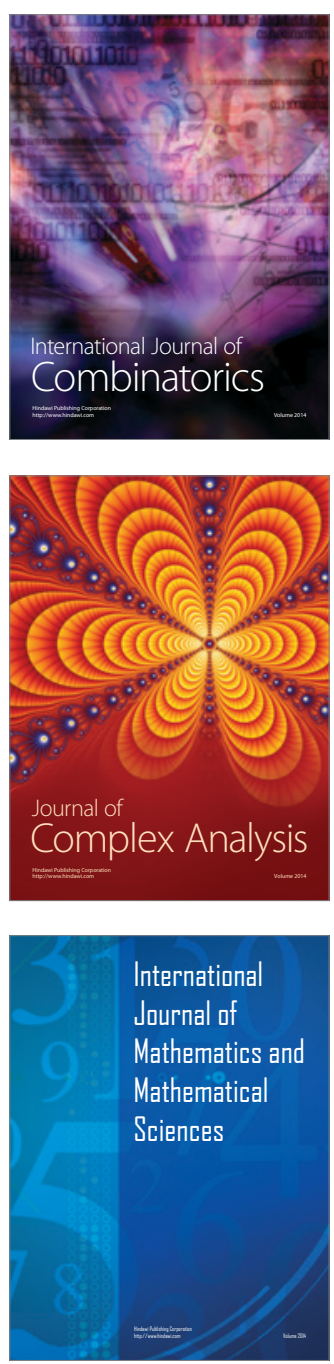
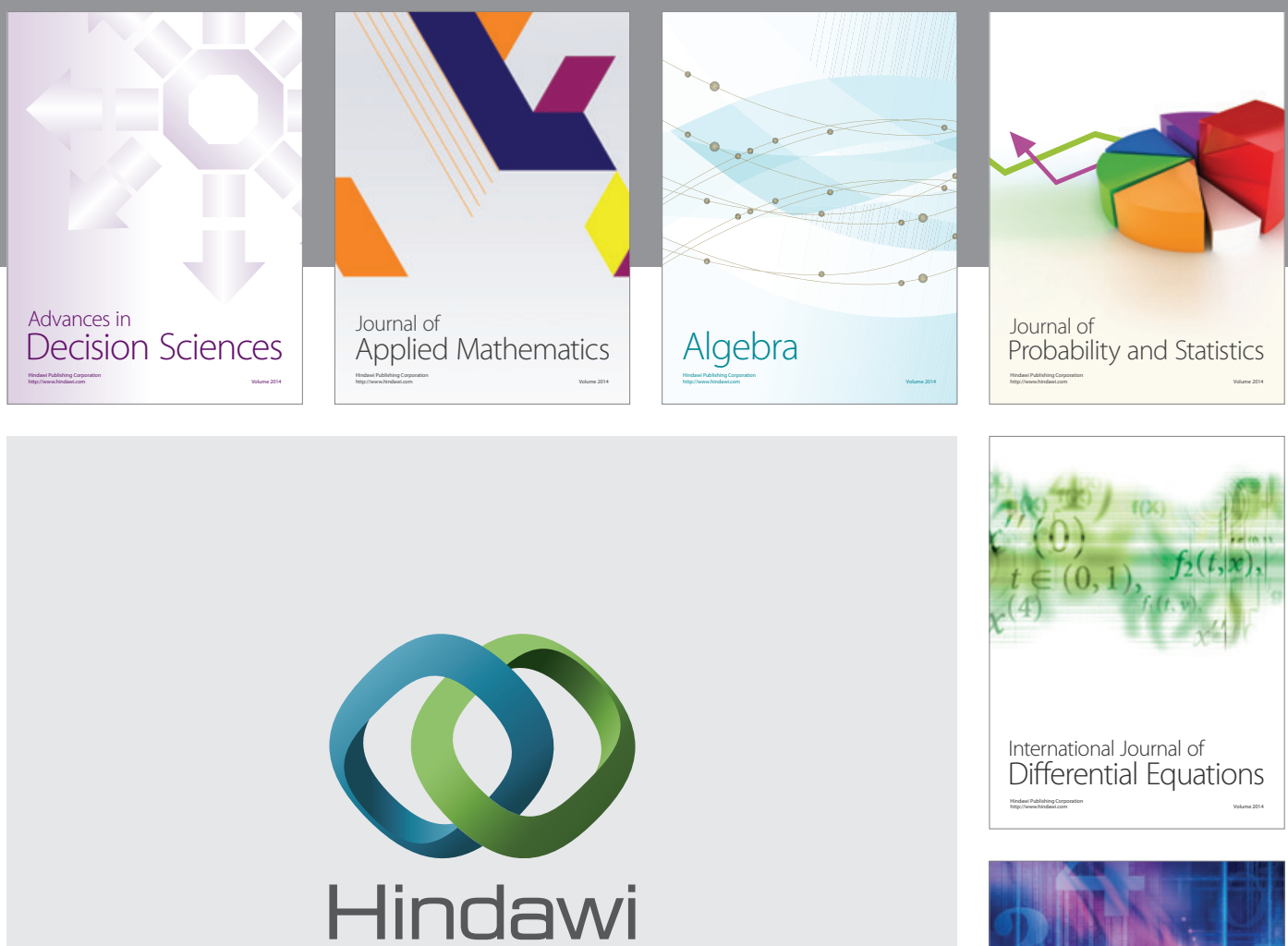

Submit your manuscripts at http://www.hindawi.com
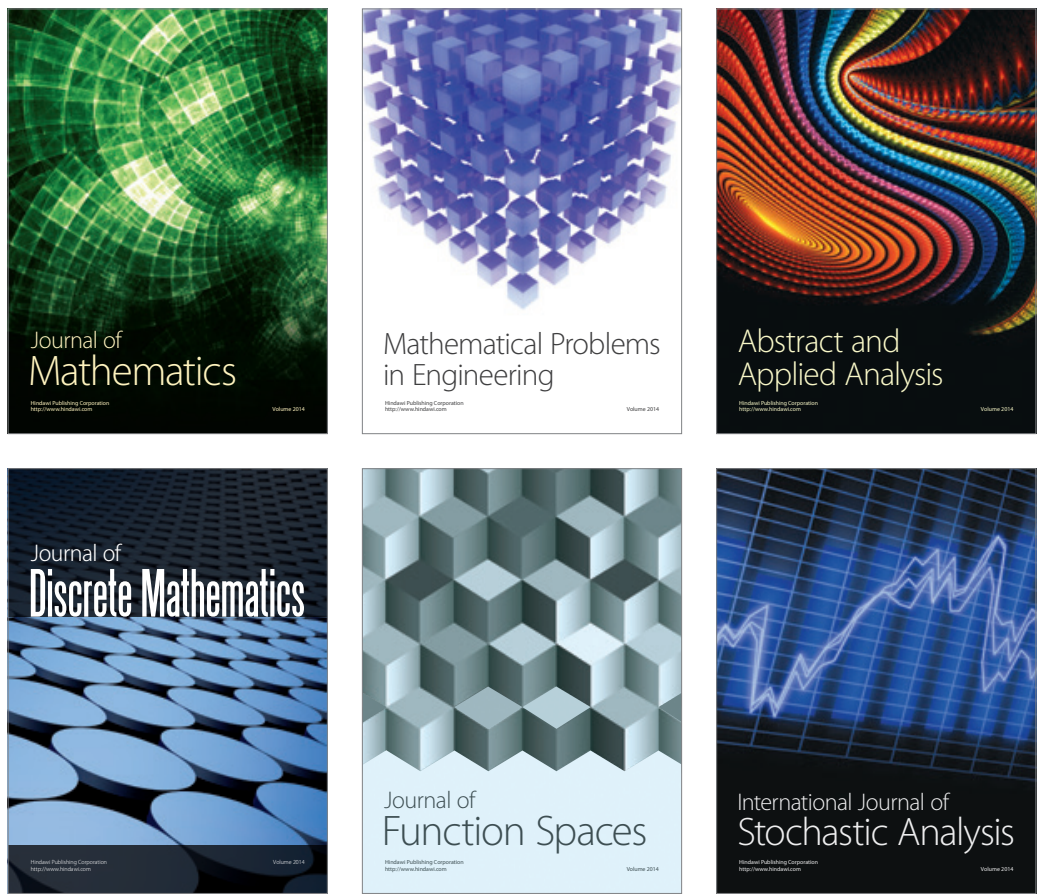

Journal of

Function Spaces

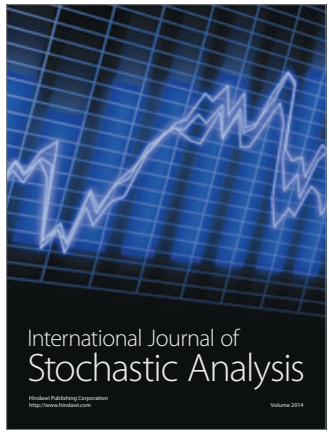

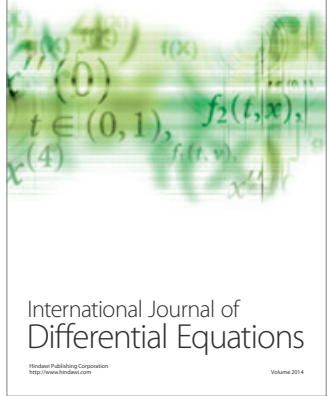
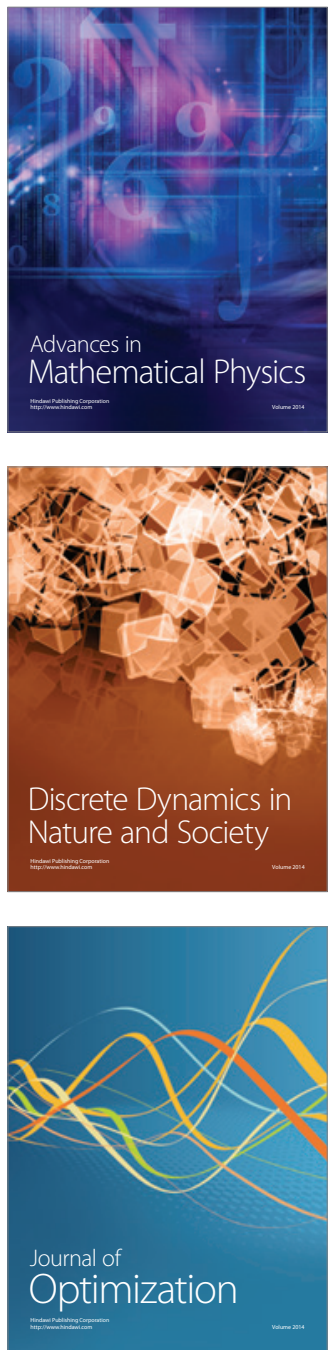